\title{
CORRECTION
}

\section{Correction: Cortical organoids model early brain development disrupted by 16p11.2 copy number variants in autism}

Jorge Urresti, Pan Zhang, Patricia Moran-Losada, Nam-Kyung Yu, Priscilla D. Negraes, Cleber A. Trujillo, Danny Antaki, Megha Amar iD, Kevin Chau (iD, Akula Bala Pramod, Jolene Diedrich, Leon Tejwani, Sarah Romero, Jonathan Sebat (D), John R. Yates III (D), Alysson R. Muotri (D) and Lilia M. lakoucheva (iD)

(c) The Author(s), under exclusive licence to Springer Nature Limited 2021

Molecular Psychiatry (2021) 26:7581; https://doi.org/10.1038/s41380-021-01289-6

Correction to: Molecular Psychiatry https://doi.org/10.1038/s41380021-01243-6, published online 26 August 2021

Figures S1-S31, originally published in the Adobe Illustrator format, were replaced with the Figs. S1-S31 in the pdf format for easier accessibility. The original article has been corrected.

\section{ADDITIONAL INFORMATION}

Supplementary information The online version contains supplementary material available at https://doi.org/10.1038/s41380-021-01289-6.
Correspondence and requests for materials should be addressed to Alysson R. Muotri or Lilia M. lakoucheva.

Reprints and permission information is available at http://www.nature.com/ reprints 